\title{
Estimating Terpene and Terpenoid Emissions From Conifer Oleoresin Composition
}

\author{
Rosa M. Flores ${ }^{1}$ and Paul V. Doskey ${ }^{1-3}$ \\ ${ }^{1}$ Department of Civil and Environmental Engineering, ${ }^{2}$ School of Forest Resources and Environmental \\ Science, ${ }^{3}$ Atmospheric Sciences Program. \\ Michigan Technological University. 1400 Townsend Dr. Houghton, MI. 49931. \\ rmflores@mtu.edu,pvdoskey@mtu.edu \\ corresponding author. Phone number: +1 906-487-2745
}

\section{A B S T R A C T}

The following algorithm, which is based on the thermodynamics of nonelectrolyte partitioning, was developed to predict emission rates of terpenes and terpenoids from specific storage sites in conifers: (1)

where $E_{i}$ is the emission rate $\left(\mu \mathrm{g} \mathrm{Cgdw}{ }^{-1} \mathrm{~h}^{-1}\right)$ and $p^{o}$ is the vapor pressure $(\mathrm{mm} \mathrm{Hg})$ of the pure liquid terpene or terpenoid, respectively, and $x_{o r}^{i}$ and $\dot{\gamma}_{o r}$ are the mole fraction and activity coefficient (on a Raoult's law convention), respectively, of the terpene and terpenoid in the oleoresin. Activity coefficients are calculated with Hansen solubility parameters that account for dispersive, polar, and H-bonding interactions of the solutes with the oleoresin matrix. Estimates of $p^{\circ}{ }_{i}$ at $25^{\circ} \mathrm{C}$ and molar enthalpies of vaporization are made with the SIMPOL.1 method and are used to estimate $p^{\circ}{ }_{i}$ at environmentally relevant temperatures. Estimated mixing ratios of terpenes and terpenols were comparatively higher above resin-acid- and monoterpene-rich oleoresins, respectively. The results indicated a greater affinity of terpenes and terpenols for the non-functionalized and carboxylic acid containing matrix through dispersive and H-bonding interactions, which are expressed in the emission algorithm by the activity coefficient. The correlation between measured emission rates of terpenes and terpenoids for Pinus strobus 
and emission rates predicted with the algorithm were very good $(R=0.95)$. Standard errors for the range and average of monoterpene emission rates were \pm 6 - $\pm 86 \%$ and $\pm 54 \%$, respectively, and were similar in magnitude to reported standard deviations of monoterpene composition of foliar oils $( \pm 38- \pm 51 \%$ and $\pm 67 \%$, respectively).

Keywords: Terpenes; Terpenoids; conifer oleoresin; Biogenic volatile organic compound (BVOC) emissions

\section{Introduction}

About $90 \%$ of reduced carbon emissions to the global troposphere $\left(1000 \pm 600 \mathrm{Tg} \mathrm{C}^{-1}\right)$ are attributed to biogenic volatile organic compounds (BVOCs; Guenther et al. 1995; Kanakidou et al. 2005). The BVOCs are rapidly photooxidized and form secondary organic aerosol (SOA; Kulmala et al., 2004). The SOA are the most abundant fine particle in the global troposphere and are hydrophilic making the aerosol effective at scattering light and forming clouds, which increases albedo and cools the atmosphere. Emissions of terpenes and terpenoids (i.e., oxygen-containing terpenes) from coniferous forests are one of the principal sources of BVOCs (Helmig et al., 2007); however, considerable uncertainty exists in developing emission inventories.

\section{Emission factors for vegetation like conifers that accumulate terpenes and terpenoids in specialized} storage tissues within leaves have been developed for many species through measurement of emission rates under various environmental conditions (Ortega et al., 2008). The emission factors are used in models to derive plant-specific emission inventories (Geron et al., 2000; Guenther et al., 2012). The monoterpene emission algorithm for specific storage tissues is based on evaporation and diffusion from the storage site (Tingey et al., 1980; Guenther et al., 1991, 1993; Geron et al., 1994). Emission rates are scaled to an emission factor determined at a standard leaf temperature and are predicted to increase 
exponentially with temperature via an emission coefficient in a manner similar to monoterpene vapor pressure. Compilations of emission factors and coefficients, which are empirically derived from measurements of emission rates, indicate the values are likely characteristic of the species of vegetation (Guenther et al., 1993; 1994). However, monoterpene emission rates are jointly regulated by synthesis and volatility of the chemical species (Niinemets et al., 2010) and are typically greater than rates predicted by changes in monoterpene vapor pressure with temperature.

Conifer oleoresins, which are synthesized by many plant organs and stored in secretory cells, cavities, canals, or glands, are composed of a volatile mixture of monoterpenes, monoterpenoids, sesquiterpenes, sesquiterpenoids and the less volatile diterpenes and diterpenoic acids (Langeheim, 2003; Zulak and Bohlmann 2010). Here, in referring to terpenoids, we do not include terpenoic acids. Composition of conifer oleoresins varies with taxonomy, phenology and age, and biotic and abiotic stresses (see, e.g., Flores, 2013), which is the reason emission factors and coefficients can vary significantly for the same species of conifer (Litvak et al., 1999; Hakola et al., 2006; Holzke et al., 2006). Terpenes and terpenoids are emitted from foliage and the stems and bole of conifers via resin blisters and induction of traumatic resin ducts by herbivore and pathogen infestations (Martin et al., 2002). Resin ducts or glands in foliage are distinct from the series of ducts in stems and the bole of the tree (Jeffrey, 1925; Hanes, 1927; Roller, 1966; Suzuki, 1979). Thus, terpenes and terpenoids are emitted from conifers (1) by exhalation from foliage stomata and (2) through evaporation from resin blisters and traumatic resin ducts on the bole of the tree.

Resin canals in conifer foliage are embedded in the mesophyll tissue that is immersed in the apoplastic fluid, which is a complex mixture of organic and inorganic electrolytes (i.e., amino acids and salts, respectively) and neutral organic compounds (i.e, sugars) (Canny, 1995; Lohaus et al., 2001). Terpenes and terpenoids diffuse from specific storage sites containing foliar oleoresin through the mesophyll into intercellular airspaces and through the substomatal cavity that is located proximal to the stoma. Cortical 
83 oleoresins rise to the surface of conifer stems and the bole and evaporate directly into the atmosphere

84 from blisters or traumatic resin ducts. Compositions of foliar and cortical oleoresins from Abies magnifica

85 and Picea sitchensis are distinct during the first 25 years of growth and become similar in the oldest

86 branches (Zavarin, 1968; Hrutfiord et al., 1974). Signatures of foliar oleoresins of Picea glauca vary

87 dramatically with phenology during the first year of growth and are invariant in mature foliage (von

88 Rudloff, 1972).

89

Here we propose a new algorithm that is based on thermodynamics of nonelectrolyte partitioning to estimate terpene and terpenoid emissions from physicochemical properties and conifer oleoresin composition. Chemical potentials $(\mu)$ of solutes in all phases of multiphase systems like foliar tissue are identical at equilibrium for constant temperature and pressure. Chemical potentials are expressed relative to some arbitrary reference state, and thus, calculating chemical potentials of solutes in various phases is not particularly useful. Conceptually, the fugacity $(f)$ of a solute in a phase is closely linked to pressure and is directly related to $\mu$ by the relation, $(d \mu=R T \ln f)_{T}$, and thus, fugacity can be used as a criterion to define equilibrium (Thibodeaux, 1996; Prausnitz et al., 1999). If the rate of partitioning of some terpenes and terpenoids between phases in foliage and the bole of the tree is rapid relative to the time required to attain equilibrium, an algorithm based on thermodynamics is suitable for estimating emission rates. Similarities between the monoterpene emission algorithm and the Clausius-Clapeyron equation are

101 discussed and a new algorithm for estimating emission rates of some terpenes and terpenoids from 102 conifers is presented. Emission fugacities for specific storage sites are derived for an oleoresin with high 103 monoterpene and resin acid contents to illustrate effects of oleoresin composition on emission fugacities 104 of terpenes and terpenoids. Measurements of oleoresin composition and foliar emissions from the same 105 species of tree are few. We use the average terpene and terpenoid composition of foliar extracts of Pinus 106 strobus reported by Toma and Bertman (2012) as the measured molar composition of foliar oils, estimate emissions from the oleoresin composition, and compare with measurements of foliar emissions from 


\section{Methods}

114 Emission fugacities are estimated for $\alpha$-pinene, germacrene D, and germacrene D-4-ol, which were 3 of

115 the most abundant terpenes and terpenoids isolated from foliar oils of Pinus strobus at UMBS over a 3-yr 116 period (Toma and Bertman, 2012). $\alpha$-Terpineol was not reported; however, the chemical species was one 117 of the more abundant monoterpenols reported by Yatagai and Sato (1986) in foliar oils of Pinus strobus 118 and is the value used in the subject study. Molar compositions of the foliar oils were used to determine 119 mole fractions of terpenes and tepenoids. Essential oil of Pinus strobus contains primarily monoterpenes 120 and resin acids, which comprise an average of 25\% and 75\%, respectively, of the oleoresin (Mirov, 1961).

121 Foliar oil composition was converted to oleoresin composition by multiplying the chemical species 122 composition in mole fraction by the average yield of essential oil from oleoresin. Molar composition of 123 cortical oleoresin of Pinus strobus has not been reported; however, comprehensive analysis of Abies 124 magnifica and Picea sitchensis (Zavarin, 1968; Hrutfiord et al., 1974) indicates foliar and cortical 125 oleoresin compositions are distinct within the first 25 years of growth and become similar thereafter.

126 Foliar and cortical oleoresin compositions were assumed equal for the subject study.

128 Measurements of foliar emissions from Pinus stobus (Ortega et al., 2008) were converted to mole fraction 129 to compare with estimates based on oleoresin composition. Foliar emissions are typically measured by 130 monitoring the change in mixing ratio of the chemical species (vol chemical species vol ${ }^{-1}$ of air) in an 131 enclosure containing the live branch of a tree. Emission measurements are reported as mass of chemical 132 species (or carbon equivalent) per mass of foliar dry weight per time. Ortega et al. (2008) report seven 
measurements of the foliar emissions $\left(\mu \mathrm{g} \mathrm{C} \mathrm{gdw}^{-1} \mathrm{hr}^{-1}\right)$ of total and individual terpenes and terpenoids from Pinus strobus. We divided emission rates of individual terpenes and terpenoids on a mole basis by the sum of the emission rates of the total terpenes and terpenoids on a mole basis to derive the mole fraction of terpenes and terpenoids in the emissions. Assuming the terpene and terpenoid vapors act as ideal gases, the product of the mole fraction and the total pressure is the partial pressure and is equivalent to the mixing ratio via the ideal gas law.

\subsection{Fugacity of the Foliar Emission Pathway}

The monoterpene emission algorithm for specific storage tissues is as follows (Tingey et al., 1980; Guenther et al., 1991, 1993; Geron et al., 1994):

$$
\ln \left(E_{i}\right)=\beta_{i}\left(T_{i}-T_{S}\right)+\ln \left(E_{S i}\right)
$$

where $E_{i}$ is the emission rate $\left(\mu \mathrm{g} \mathrm{C} \mathrm{gdw}{ }^{-1} \mathrm{~h}^{-1}\right)$ at leaf temperature $T_{i}(\mathrm{~K}), E_{S i}$ is an emission factor $(\mu \mathrm{g} \mathrm{C}$ $\left.\mathrm{gdw}^{-1} \mathrm{~h}^{-1}\right)$ that is $E_{i}$ normalized to the leaf temperature $T_{S}(303 \mathrm{~K})$, and $\beta_{i}\left(\mathrm{~K}^{-1}\right)$ is an emission coefficient. Resin ducts in foliage, which are the specific storage tissues of the monoterpenes, are located in the mesophyll that is immersed in apoplastic fluid containing a mixture of electrolytes and sugars. Intercellular airspaces connect the mesophyll to the substomatal cavity. Terpenes and terpenoids are in a dynamic equilibrium between oleoresin, apoplastic fluid, the mesophyll, and air in the substomatal cavity and fugacities of chemical species in all phases are equal at equilibrium. The fugacity of a pure liquid terpene or terpenoid in equilibrium with pure water is given by the following: 
where $f_{A 3}$ and $f_{A 2}$ are fugacities of the pure liquid solute and water, respectively, $x_{A 3}$ is the mole fraction of

159 the pure liquid solute (which is assumed to contain a negligible amount of water, and thus, the value is 1),

$160 x_{A 2}$ is the mole fraction of the pure liquid solute in pure water, $\gamma_{A 3}$ is the activity coefficient (on a Raoult's

161 law convention) of the pure liquid solute (which is a pure liquid, and thus, the value is 1 ), $\gamma_{A 2}$ is the

162 activity coefficient (on a Raoult's law convention) of the pure liquid solute in pure water, and $f_{A 3}^{\circ}$ and $f_{A 2}^{\circ}$

163 are reference fugacities of the pure liquid solute and pure liquid solute in water, which by definition are

164 the vapor pressure of the pure liquid solute. Conventions for subscripts are as follows: the letter

165 designates the chemical species and numerals 1,2,3, and 4 designate the phases, which are air, water,

166 pure liquid solute, and oleoresin, respectively.

167

168 For a pure liquid solute in equilibrium with pure water Eq. (2) reduces to the following:

$$
\gamma_{A 2}=\frac{1}{x_{A 2}}
$$

172 The relationship between the activity coefficient and the mole fraction of a pure solute in pure water is as 173 follows (Acree, 1984):

$$
\ln \gamma_{i}=K\left(1-x_{i}\right)^{2}
$$

177 where $K$ is a constant that is a function of the solute. Many nonelectrolytes like the terpenes and 178 terpenoids are sparingly soluble in water, and thus, $x_{i}$ is much less than 1 and $\gamma_{i}$ is not proportional to 179 concentration and instead approaches a constant value $\left(e^{K}\right)$. Thus, activity coefficients (on a Raoult's law convention) for many non-electrolytes can be calculated as follows: 


$$
\gamma_{A 2}=\frac{1}{x_{A 2}^{\circ}}
$$

where $x_{A 2}^{o}$ is the aqueous solubility of the liquid solute (on a mole fraction basis).

Activities of terpenes and terpenoids in the apoplastic fluid, which contains a mixture of electrolytes and sugars, are related to the aqueous solubility as follows:

$$
a_{A 2^{*}}=\gamma_{A 2^{*}} c_{A 2}^{\circ}
$$

where $a_{A 2 *}$ and $\gamma_{A 2 *}$ are the activity and activity coefficient (on a Henry's law convention) of the substance in the apoplastic fluid, respectively, and $c^{o}$ is the aqueous solubility $\left(\mathrm{mol} \mathrm{m}^{-3}\right)$ of a sparingly soluble, nonelectrolyte like a terpene or terpenoid. Values of $\gamma_{A 2 *}$ are sensitive to the electrolyte and nonelectrolyte composition of the apoplastic fluid. Setschenow (1889) developed the following empirical relationship that can be used to describe the effect of added salt on solute solubility:

$$
\log \left(\frac{\gamma}{\gamma_{0}}\right)=\log \left(\frac{S_{0}}{S}\right)=k_{S} C_{S}
$$

where $\gamma_{0}$ and $\gamma$ are the solute activity coefficients (on a Henry's law convention) for the solute in water and saline solution, $\mathrm{S}_{0}$ and $\mathrm{S}$ are the solute solubility in water and saline solution, respectively, $k_{S}$ is the Setschenow constant, and $C_{S}$ is the total salt concentration (expressed as molality) in solution. The value of $\gamma_{0}$ for pure water is 1.0 and for dilute solutions like apoplastic fluids Eq. (7) is rewritten as follows:

$$
\log \gamma_{A 2^{*}}=k_{S} C_{*}
$$


where $C_{*}$ is the concentration (M) of electrolytes and non-electrolytes in the apoplastic fluid.

208 Copolovici and Niinemets (2007) evaluated salting-out and salting-in effects of apoplastic electrolytes and sugars, respectively, on limonene and linalool partitioning from water into air and octanol to derive values of $k_{s}$. Activities of nonelectrolytes like limonene and linalool are expected to be greater than

211 solubilities in apoplastic fluids containing electrolytes due to the salting-out effect, and thus, values of $\gamma_{A 2 *}$

212 for nonelectrolytes like limonene and linalool in apoplastic fluids composed of electrolytes would be

213 greater than 1. However, in apoplastic fluids containing nonelectrolytes like sugars, activities of limonene 214 and linalool are expected to be less than the solubilities in apoplastic fluids due to the salting-in effect and values of $\gamma_{A 2 *}$ would be less than 1. Copolovici and Niinemets (2007) reported salting-out coefficients for

216 limonene and linalool were 0.0231 and 0.167 , respectively, in aqueous solutions of potassium chloride at $21730^{\circ} \mathrm{C}$ and average salting-in coefficients for limonene and linalool in aqueous solutions of glucose and 218 sucrose were -1.0159 and -0.0173 , respectively. Lohaus et al. (2001) reported average levels of 32.3 and $2194.3 \mathrm{mM}$ of inorganic electrolytes and sugars, respectively, in apoplastic fluids of several agricultural crops. At these concentrations, values of $\gamma_{A 2 *}$ calculated for terpenes and terpenoids in apoplastic fluids using Eq. (8) are 1.0, and thus, activities of the terpenes and terpenoids in the apoplastic fluid are equivalent to aqueous solubilities [Eq. (6)]. If values of $\gamma_{A 2^{*}}$ (on a Henry's law convention) for the 223 terpenes and terpenoids in apoplastic fluids are 1.0, then values of $\gamma_{A 2}$ (on a Raoult's law convention) do 224 not require a correction for salting-in or -out effects.

The equilibrium condition for terpenes and terpenoids in the oleoresin with the apoplastic fluid is represented as follows:

$$
f_{A 4}=x_{A 4} \gamma_{A 4} f_{A 4}^{\circ}=x_{A 2 *} \gamma_{A 2} f_{A 2}^{\circ}=f_{A 2 *}
$$


231 where $f_{A 4}, x_{A 4}, \gamma_{A 4}$, and $f_{A 4}^{\circ}$ are the fugacity, mole fraction, activity coefficient, and reference fugacity,

232 respectively, of the individual terpenes and terpenoids in the oleoresin and $f_{A 2^{*}}$ and $x_{A 2^{*}}$ are the fugacity

233 and mole fraction of the individual terpenes and terpenoids in the apoplastic fluid. Reference fugacities,

$234 f^{\circ}{ }_{A 4}$ and $f^{\circ}{ }_{A 2}$, are defined as the vapor pressure of the pure liquid solute. Combining Eqs. (9) and (5) and replacing mole fraction by molar concentration results in the following:

$$
c_{A 2^{*}}=x_{A 4} \gamma_{A 4} c_{A 2}^{\circ}
$$

where $c_{A 2}$ is the concentration $\left(\mathrm{mol} \mathrm{m}^{-3}\right)$ of a terpene or terpenoid in the apoplastic fluid and $c^{\circ}{ }_{A 2}$ is the aqueous solubility $\left(\mathrm{mol} \mathrm{m}^{-3}\right)$. The molar concentration is proportional to the mole fraction in dilute solutions like the apoplastic fluid, and thus, mole fractions are replaced by molar concentrations in Eq. (10).

Terpenes and terpenoids that dissolve in the apoplastic fluid will partition to the aqueous environment of the mesophyll, which is in contact with intercellular airspaces leading to the substomatal cavity. Assuming dissolution in octanol and the mesophyll are similar, the concentration of the chemical species in octanol is calculated as follows:

$$
c_{A O}=c_{A 2^{*}} K_{O W}
$$

where $c_{A O}$ is the concentration $\left(\mathrm{mol} \mathrm{m}^{-3}\right)$ of the substance in octanol and $K_{O W}$ is the dimensionless octanol/water partition coefficient (vol water vol $^{-1}$ octanol). If the substance were partitioning directly from the apoplastic fluids to the intercellular airspace, the concentration of the substance in the intercellular airspace would be calculated as follows: 


$$
c_{A 1 F}=c_{A 2^{*}} K_{A W}
$$

258 where $c_{A I F}$ is the concentration in the substomatal cavity of foliage $\left(\mathrm{mol} \mathrm{m}^{-3}\right)$ and $K_{A W}$ is the dimensionless

259 Henry's law constant (vol water vol ${ }^{-1}$ air). Dividing Eq. (12) by Eq. (11) is the definition of the

260 dimensionless air/octanol partition coefficient $\left(K_{A O}\right.$, vol octanol vol $^{-1}$ air $)$, which is ratio of concentration

261 of chemical species in air and octanol. Thus, at equilibrium in the 3-phase system (i.e., apoplastic fluid,

262 the aqueous environment of the mesophyll, and airspace of the substomatal cavity) fugacities of the

263 chemical species in the phases are equal, and $c_{A I F}$ is essentially governed by Eq. (12). Making the

264 substitution for $\mathrm{c}_{\mathrm{A} 2^{*}}$ given by Eq. (10) into Eq. (12) and converting $c_{A I F}$ to mole fraction results in the

265 following expression that is used to calculate the mole fraction of the substance above the mesophyll in

266 the substomatal cavity:

$$
y_{A 1 F}=\frac{x_{A 4} \gamma_{A 4} c_{A 2}^{\circ} K_{A W} R T}{P}
$$

where $y_{A I F}$ is the mole fraction of the terpene or terpenoid in the substomatal cavity, $R$ is the ideal gas law constant $\left(8.314 \mathrm{~Pa} \mathrm{~m}^{3} \mathrm{~K} \mathrm{~mol}^{-1}\right)$ and $T$ and $P$ are the temperature and total pressure, respectively (assumed to be $298.15 \mathrm{~K}$ and $1.01325 \times 10^{5} \mathrm{~Pa}$ for the subject study). Mole fractions of the terpenes and terpenoids in the substomatal cavity are the same as partial pressures, which are equivalent to mixing ratios of the chemical species $\left(\operatorname{vol~vol}^{-1}\right)$, when $P$ is expressed in atm.

\subsection{Fugacity of the Bole Emission Pathway}

Terpenes and terpenoids evaporate from resin blisters and traumatic resin ducts on the bole of the tree directly into the atmosphere and are estimated from the composition of the oleoresin and species vapor pressure as follows: 


$$
y_{A 1 B}=\frac{x_{A 4} \gamma_{A 4} p_{A}^{\circ}}{P}
$$

where $y_{A l B}$ is the mole fraction of a terpene and terpenoid in air above resin blisters and traumatic resin ducts on the bole of the tree. Dividing the fugacity of terpenes or terpenoids above resin blisters and traumatic resin ducts by the fugacity of terpenes or terpenoids in the substomatal cavity of foliage, which is represented by Eq. (13), results in the following:

$$
\frac{y_{A 1 B}}{y_{A 1 F}}=\frac{p_{A}^{\circ}}{c_{A 2}^{\circ} K_{A W} R T}
$$

At infinite dilution, partitioning of the terpenes and terpenoids between air and the apoplastic fluids is governed by Henry's law, which is the ratio of $p_{A}^{\circ}$ to $c_{A 2}^{\circ}$ when the aqueous solubility of the chemical species is $<1 \times 10^{4} \mathrm{M}$ (Mackay and Shiu, 1981). The ratio, $p_{A}^{\circ} / c_{A 2}^{\circ}$ is the Henry's law constant $(H ; \mathrm{Pa}$ $\mathrm{m}^{3} \mathrm{~mol}^{-1}$ ) that is equivalent to $K_{A W} \times R T$, and thus, fugacities of terpenes and terpenoids for the foliar and bole pathways are identical. Thus, Eq. (14) can be used to calculate emission fugacities for terpenes and terpenoids when the foliar and cortical oleoresin compositions are the same and the rate of partitioning of the terpenes and terpenoids between phases in foliage and the bole of the tree is rapid relative to the time required to attain equilibrium.

\subsection{Activity Coefficients of Terpenes and Terpenoids in Oleoresin}

Values of activity coefficients for terpenes and terpenoids in oleoresin matrices [ $\gamma_{A 4}$ in Eq. (13)] were derived using Hansen solubility parameters (Hansen, 2007). The parameters include contributions from dispersive, polar, and H-bonding interactions between the solute and polymer matrix and are designated 

and solubility parameters for terpenes, terpenoids, and 2 oleoresin matrices (Table 1). Activity coefficients for terpenes and terpenoids in oleoresin were estimated as follows (Hansen, 2007):

$$
\ln \gamma_{o r}=\frac{V_{i}}{R T}\left[\left(\delta_{d}^{o r}-\delta_{d}^{i}\right)^{2}+0.25\left(\delta_{p}^{o r}-\delta_{p}^{i}\right)^{2}+0.25\left(\delta_{h}^{o r}-\delta_{h}^{i}\right)^{2}\right]+\left\lfloor\ln \left(\frac{V_{i}}{V_{o r}}\right)+1-\frac{V_{i}}{V_{o r}}\right\rfloor
$$

where $\dot{\gamma}_{O R}$ is the activity coefficient for the terpene or terpenoid in the oleoresin, $V_{i}$ and $V_{o r}$ are molar volumes of the terpene or terpenoid and oleoresin $\left(\mathrm{cm}^{3} \mathrm{~mol}^{-1}\right)$, respectively, and RT is $592 \mathrm{cal} \mathrm{mol}^{-1}$ at 298.15 K. Hypothetical oleoresin matrices were selected to demonstrate effects of oleoresin composition on emission fugacities. Analyses of several species of Pinus indicate mole fractions of monoterpenes and resin acids in oleoresin $\left(x_{M T}\right.$ and $x_{R A}$, respectively) are about 0.20 and 0.80 (Mirov, 1961). Molecular analyses of the cortical oleoresin of Pinus contorta (Lewinsohn et al., 1993) indicate $\alpha$-pinene and levopimaric acid are the principal monoterpene and resin acid in the oleoresin. Hypothetical oleoresins with a high monoterpene content $\left(\mathrm{OR}_{\mathrm{MT}} ; 80 \% \alpha\right.$-pinene and $20 \%$ levopimaric acid) and resin acid content $\left(\mathrm{OR}_{\mathrm{RA}} ; 20 \% \alpha\right.$-pinene and $80 \%$ levopimaric acid) were selected as model cases and values of $\dot{\gamma}_{\text {or }}$ were estimated with Eq. (14) (Table 1). Values of $\dot{\gamma}_{o r}$ estimated with the universal functional group activity coefficient (UNIFAC) model (Fredenslud et al., 1975; Hansen et al., 1991) were similar.

\section{Results and discussion}


328 Mixing ratios of the non-functionalized terpenes, $\alpha$-pinene and germacrene $\mathrm{D}$, above oleoresin with an $32980 \%$ resin acid content were $19 \%$ and $55 \%$ higher, respectively, than the mixing ratios above oleoresin 330 with a $80 \%$ monoterpene content (Fig. 1). Averages of the activity coefficients of monoterpenes and 331 sesquiterpenes in the nonpolar, monoterpene-rich oleoresin, with the exception of myrcene, were 1.03 and 3321.05 , respectively, and 1.26 and 2.11, respectively, in the polar, resin-acid-rich oleoresin (Table 1). The 333 activity coefficient of myrcene, which lacks a cyclic moiety, was 1.31. The results indicate the non-polar, 334 terpene solutes were more soluble in the monoterpene-rich oleoresin, which was similar in structure and 335 functionality. Dispersive interactions contributed $74 \%$ of the total interactions (i.e., $\Sigma$ dispersive, polar, 336 and H-bonding) involved in solubility of terpenes in the monoterpene-rich oleoresin. Mixing ratios of germacrene $\mathrm{D}$ above the resin acid-rich oleoresin compared to the monoterpene-rich oleoresin were much greater than $\alpha$-pinene, which demonstrates the effect of solute molecular size on solubility.

340 Mixing ratios of the terpenols, $\alpha$-terpineol and germacrene D-4-ol, above oleoresin with an $80 \%$ 341 monoterpene content were 58\% and 10\%, higher, respectively, than the mixing ratios above oleoresin 342 with an $80 \%$ resin acid content (Fig. 1). $\alpha$-Terpineol exhibited a greater disparity between activity 343 coefficients for the monoterpene- and resin-acid-rich oleoresin than germacrene D-4-ol, which explains 344 higher mixing ratios of $\alpha$-terpineol than germacrene D-4-ol above the monoterpene-rich oleoresin relative 345 to the resin-acid-rich oleoresin. Contributions of $\mathrm{H}$-bonding interactions to the total interactions involved 346 in the solubility of $\alpha$-terpineol and germacrene D-4-ol were 33.4 and 31.2, respectively (Table 1), which 347 explains the relatively lower mixing ratios above the resin-acid-rich oleoresin that contained a carboxylic 348 acid moiety. 
352 The correlation between emissions of terpenes and terpenoids from Pinus strobus and the mole fraction in

353 foliar oleoresin was very good $(R=0.92)$, with the exception of myrcene, camphene, and germacrene $\mathrm{D}$

354 (Fig. 2). Emission rates are estimated by measuring the change in partial pressure (or mixing ratio) of the

355

where $p^{\circ}$ is the vapor pressure of the liquid solute, $A_{i}$ is a constant related to the boiling point at atmospheric pressure (i.e., the normal boiling point), $\Delta H_{v i}\left(\mathrm{~kJ} \mathrm{~mol}^{-1}\right)$ is the molar enthalpy of vaporization of the liquid solute at temperature $T(\mathrm{~K})$, and $R\left(8.314 \times 10^{-3} \mathrm{~kJ} \mathrm{~mol}^{-1} \mathrm{~K}^{-1}\right)$ is the ideal gas law constant. Over relatively small temperature ranges, $\Delta H_{v i}$ can be assumed to be a constant and the integrated form of the Clausius-Clapyeron equation can be written as follows: terpene or terpenoid within an enclosure containing the branch of a live tree. Thus, emission rates should be related to oleoresin composition and solute vapor pressure via Eq. (14) provided the rate of partitioning of terpenes and terpenoids between phases in foliage and the bole of the tree is rapid relative to the time required to attain equilibrium.

The Clausius-Clapyeron equation relates changes in the vapor pressure of a liquid solute with temperature to the molar enthalpy of vaporization and is written as follows:

$$
p_{i}^{\circ}=A \exp \left(-\frac{\Delta H_{v i}}{R T}\right)
$$

$$
\ln p_{i 2}^{\circ}=\frac{\Delta H_{v i}}{R}\left(\frac{1}{T_{1}}-\frac{1}{T_{2}}\right)+\ln p_{i 1}^{\circ}
$$

Values of $\Delta H_{v i}$ and $p^{\circ}{ }_{\mathrm{i}}$ at $25^{\circ} \mathrm{C}$ for the terpenes and terpenoids, which were estimated by the SIMPOL.1 method (Pankow and Asher, 2008), are presented in Table 2. 
376 Similarities exist between the monoterpene algorithm [Eq. (1)] and the integrated form of the Clausius-

377 Clapyeron equation [Eq. (18)]. The monoterpene algorithm is empirically derived and relates

378 monoterpene emission rate, which is a measure of the change in partial pressure (or mixing ratio) of the

379 monoterpene emitted by vegetation over time, to temperature. However, the Clasius-Clapyeron equation

380 expresses the relationship between vapor pressure of a liquid solute and temperature. Tingey et al. (1991)

381 observed a correlation between monoterpene vapor pressure and emission rate when expressed as $\mathrm{mm} \mathrm{Hg}$

382 and $\mu \mathrm{g} \mathrm{Cgdw}^{-1} \mathrm{~h}^{-1}$, respectively. The average value of $\beta$ for $\alpha$-pinene emitted from 7 species of Pinus

383 reported by Guenther et al. (1993) was $0.099 \pm 0.021( \pm 21 \%)$. Geron et al. (1994) report a value of $3.0 \mu \mathrm{g}$

$384 \mathrm{C} \mathrm{gdw}^{-1} \mathrm{~h}^{-1}$ for $E_{S}$ for Pinus. A graph of $\ln E$ and $p^{\circ}$ versus $T^{-1}$ for $\alpha$-pinene using the average and range of

$385 \beta$ values and $E_{S}$ (Fig. 3) demonstrates the relationship observed by Tingey et al. (1991). When values of $E$

386 for $\alpha$-pinene at $25^{\circ} \mathrm{C}$ and $20^{\circ} \mathrm{C}$ are estimated with Eq. (1) using the widest range of $\beta$ values and a single

387 value of $E_{S}$, the estimates vary by $22 \%$ and $43 \%$, respectively.

388

389 The partial pressure of a terpene or terpenoid in equilibrium with oleoresin is given by the following:

$$
p_{i}=x_{o r}^{i} \gamma_{o r} p_{i}^{\circ}
$$

392

where $p_{i}$ and $p_{i}^{o}$ are the partial and vapor pressure, respectively, and $x_{o r}^{i}$ is the mole fraction of the pure liquid solute in the oleoresin. The vapor pressure of the oleoresin is the sum of the partial pressures of the pure liquid solutes in the oleoresin as follows:

396

$$
p_{O R}^{o}=\sum_{i=1}^{n} x_{o r}^{i} \gamma_{o r} p_{i}^{\circ}
$$


where $p_{O R}^{\circ}$ is the vapor pressure of the oleoresin and $n$ is the number of terpenes and terpenoids in the oleoeresin. The value of $E_{S}$ is essentially the partial pressure of the terpene or terpenoid at $30^{\circ} \mathrm{C}$, which is

401 a fraction of $p^{\circ}{ }_{i}$ also at $30^{\circ} \mathrm{C}$ that is determined by $x_{o r}^{i}$ and interactions of the solute with oleoresin quantified by $\dot{\gamma}_{o r}$. Unlike $A_{i}$ in the Clausius-Clapeyron equation [Eq. (17)], $E_{S}$ for a terpene or terpenoid 403 will vary by conifer species and oleoresin composition. Thus, estimates of $E$ using Eq. (1) and a single 404 value of $E_{S}$ to represent all Pinus species are thermodynamically inaccurate.

Data from measurements of emission rates of several monoterpenes as a function of Pinus elliotii needle temperature (Tingey et al., 1980) are plotted with monoterpene vapor pressures in Fig. 4. Structures of $\alpha$ pinene and $\beta$-pinene are very similar, and thus, estimates of $\Delta H_{v i}$ and $p^{\circ}{ }_{i}$ were the same (Table 2). Lines for vapor pressures and emission rates are nearly parallel, with the exception of $\alpha$-pinene/ $\beta$-pinene that exhibits some deviation above $30^{\circ} \mathrm{C}$. Slopes of the lines that relate vapor pressures of $\alpha$-pinene $/ \beta$-pinene and myrcene to temperature are equal to $\Delta H_{v i} R^{-1}$ via Eq. (18). Values of $\Delta H_{v i}$ for $\alpha$-pinene/ $\beta$-pinene and myrcene are 54.2 and $56.3 \mathrm{~kJ} \mathrm{~mol}^{-1}$, respectively. Products of the slopes of the lines for emission rates of $\alpha$-pinene, $\beta$-pinene, and myrcene and $R$ are $50.3,57.7$, and $57.3 \mathrm{~kJ} \mathrm{~mol}^{-1}$, respectively, which are within

$414 \pm 7.6, \pm 6.2$, and $\pm 1.7 \%$ of the estimated values of $\Delta H_{v i}$ for the monoterpenes (Table 2). The analysis

415 indicates $\beta$ in Eq. (1) is specific to the terpene or terpenoid and not to the species of vegetation. Lines for 416 the monoterpene emissions rates have unique y-intercepts that are related to oleoresin composition 417 through $x_{i 4}$ and $\gamma_{i 4}$, which together with $p^{\circ}{ }_{I}$ determine $p_{i}$. Thus, emission rates of terpenes and terpenoids 418 from oleoresin should be related to the pure liquid solute vapor pressure as follows:

$$
E_{i}=x_{o r}^{i} \gamma_{o r} p_{i}^{\circ}
$$

422 where $E_{i}$ and $p^{\circ}$ are the emission rate $\left(\mu \mathrm{g} \mathrm{C} \mathrm{gdw}^{-1} \mathrm{~h}^{-1}\right)$ and vapor pressure $(\mathrm{mm} \mathrm{Hg})$ of the pure liquid 423 solute, respectively. 
425 Data for terpene and terpenoid composition of foliar oils from Pinus strobus (Toma and Bertman, 2012)

426 and essential oil content of oleoresin (Mirov, 1961) were used to predict $x_{o r}^{i}$. Values of $\gamma_{o r}$ and $p^{\circ}{ }_{i}$ at

$42730^{\circ} \mathrm{C}$ were estimated using Eq. (16) and Eq. (18), respectively, and were used in Eq. (21) to predict

428 emission rates at $30^{\circ} \mathrm{C}$ (Table 2). Ortega et al. (2008) report measurements of terpene and terpenoid

429 emissions (normalized to $30^{\circ} \mathrm{C}$ ) from Pinus strobus (Table 2). The correlation between measured and

430 predicted emission $(R=0.95$; Fig. 5$)$ is slightly better than the correlation between mole fraction in the

431 emissions and foliar oleoresin $\left(R=0.92\right.$; Fig. 2), which is likely due to the incorporation of $\dot{\gamma}_{o r}$ in the

432 emission prediction. The range and average of the standard error between the measured and predicted

433 emission of the monoterpenes was $\pm 6- \pm 86 \%$ and $\pm 54 \%$, respectively. Standard errors were about $200 \%$

434 for $\alpha$-terpineol, $\beta$-caryophyllene, and germacrene $\mathrm{D}$.

435

436 Reliable estimates of $x_{o r}^{i}$ depend on an accurate value of the volatile liquid content of oleoresin. Oleoresin 437 is composed of essential oil, which contains terpenes and terpenoids, and rosin that is composed of 438 diterpenoic resin acids. Mirov (1961) determined yields of essential oil from oleoresins via vacuum 439 distillation and gravimetric analysis. However, the rosin fraction remaining after distillation might also 440 contain nonvolatile resin acids, which would lead to an error in estimates of $x_{o r}^{i}$. Toma and Bertman 441 (2012) sampled 1-yr old Pinus strobus needles and analyzed the foliar oil content of about 90 trees at 442 UMBS from 2008-2010, which was the basis for the average composition of foliar oils for the subject 443 study. Emission rates predicted by assuming foliar oils represent the volatile liquid content of oleoresin

444 (Table 2) grossly overestimated emission rates for several monoterpenes, which indicates the volatile 445 liquid content of oleoresin is greater than the foliar oil content.

447 Large disparities between measured and predicted emission rates for Pinus strobus were expected. Foliar 448 oil composition of the same species of conifer can vary widely with phenology and age and biotic and 
abiotic stresses (see, e.g., Flores, 2013). Toma and Bertman (2012) sampled branches of understory trees of Pinus strobus at a height of $1.3 \mathrm{~m}$ and branches of large canopy trees were sampled at heights of 6-17 $\mathrm{m}$ and 2-4 $\mathrm{m}$. The range and average of the standard deviations of the monoterpene concentrations in foliar oils $(n=210)$ were $\pm 38- \pm 51 \%$ and $\pm 67 \%$, respectively. Terpene and terpenoid emission rates were measured at the UMBS during the 2004-2006 growing seasons (Ortega et al., 2008). Uncertainties in

454 foliar oil composition are similar in magnitude to values of standard errors that were observed between 455 the correlation of measured and predicted monoterpene emission rates. Emissions of $\alpha$-terpineol were predicted using the foliar oil composition of Pinus strobus in Tsukuba, Japan (Yatagai and Sato, 1986), and thus, the significant disagreement between measured and predicted emissions was expected.

Biogenic emission models use values of $E_{S i}$ for broad classes of plant functional types to estimate BVOC emissions at regional and global scales (see, e.g., Guenther et al., 2012). Values of $\beta$ are used together with $E_{S i}$ to estimate $E_{i}$ at environmentally relevant temperatures using the monoterpene exponential temperature response function of Eq. (1). According to Eq. (21), a measurement of $E_{i}$ normalized by $p_{I}^{\circ}$ is essentially a measure of $x_{o r}^{i} \dot{\gamma}_{o r}$. Based upon the analysis here, compilations of $E_{S i}$ for various species of conifers can be used to estimate terpene and terpenoid emissions as follows:

$$
E_{i}=E_{S i} \exp \left[\left(\frac{\Delta H_{v i}}{R}\right)\left(\frac{1}{T_{S}}-\frac{1}{T_{i}}\right)\right]
$$

468 However, values of $E_{S i}$ vary in concert with oleoresin composition, which fluctuates considerably with conifer species (see, e.g., von Rudloff, 1975). Thus, to improve BVOC estimates requires development of conifer-specific emission inventories. Furthermore, application of the algorithm assumes terpenes and

471 terpenoids are released from specific storage sites and partitioning between phases in foliage is rapid relative to the time required to attain equilibrium. Release of some terpenes and terpenoids from the 
473 stoma can be delayed through nonspecific storage in hydrophobic and hydrophillic plant tissues within

474 the leaf (Niinemets and Reichstein, 2002; Niinemets et al., 2004). Thus, the time scale over which

475 emission measurements and predictions are compared is critical. Eav (2011) observed emissions of

476 myrcene from Pinus nigra foliage during light and dark periods; however, myrcene was not found in

477 foliar oils. Biosynthesis of myrcene might be light induced and temporarily stored in non-specific storage

478 sites of conifer foliage.

\section{Conclusions}

A new algorithm for estimating emission rates of terpenes and terpenoids from specific storage sites, which is based on thermodynamics of nonelectrolyte partitioning with a polymer matrix, was developed to estimate emissions from conifer oleoresin composition. Emissions through leaf stomata and from resin blisters and traumatic resin ducts induced by herbivore and pathogen infestations are calculated by the same algorithm and depend on the mole fraction of terpene or terpenoid in the oleoresin, activity coefficient (on a Raoult's law convention), and vapor pressure of the pure liquid solute. The SIMPOL.1 method (Pankow and Asher, 2008) was used to estimate vapor pressures of terpenes and terpenoids at $25^{\circ} \mathrm{C}$ and molar enthalpies of vaporization $\left(\Delta H_{v i}\right)$, which can be used to estimate vapor pressures at environmentally relevant temperatures using the integrated form of the Clausius-Clapyeron equation.

491 Hansen solubility parameters (Hansen, 2007), which include contributions from dispersive, polar, and Hbonding interactions between solute and oleoresin, were used to derive values of the activity coefficients.

493 Solubilities of $\alpha$-pinene and germacrene D were largely the result of dispersive interactions with 494 monoterpene-rich oleoresin, which was more similar in structure and functionality to the solutes than 495 resin-acid-rich oleoresin. Thus, mixing ratios of non-functionalized terpenes above the monoterpene-rich 496 oleoresin were lower compared to mixing ratios above the resin-acid-rich oleoresin. $\alpha$-Terpineol and 497 germacrene D-4-ol, can form H-bonds with resin-acid-rich oleoresin that included a carboxylic acid 
moiety, and thus, mixing ratios of the terpenols above monoterpene-rich oleoresin were higher compared to mixing ratios above resin-acid-rich oleoresin.

The emission rate algorithm is based on the Clausius-Clapyeron equation, which relates changes in the vapor pressure of a liquid solute with temperature to $\Delta H_{v i}$. Values of $\Delta H_{v i}$ for $\alpha$-pinene, $\beta$-pinene, and myrcene derived from plots of the variation of monoterpene emission rate for Pinus elliotii with needle

504 temperature (Tingey et al., 1980) were in good agreement with values estimated by the SIMPOL.1

505 method (Pankow and Asher, 2008). The correlation between measurements of terpene and terpenoid 506 emission rates from Pinus strobus (Ortega et al., 2008) and predictions based on the emission rate 507 algorithm was very good. The average standard error for the monoterpenes was quite large $( \pm 54 \%)$.

508 However, standard errors between measured and predicted emission rates were similar in magnitude to 509 uncertainties in molar composition of foliar oils reported by Toma and Bertman (2012).

511 Developing conifer-specific emission inventories from oleoresin composition is a promising approach for 512 reducing uncertainties in predictions of BVOC emissions. Collection and analysis of foliage to determine 513 oleoresin composition (see, e.g., Lewinsohn et al., 1993) is much less complicated than sampling and 514 analytic techniques for measuring emissions (see, e.g., Ortega et al., 2008). However, oleoresin 515 composition is related to several factors including taxonomy, phenology and age, and abiotic and biotic 516 stresses (see, e.g., Flores, 2013), which need to be addressed when developing emission inventories from 517 oleoresin composition or from direct measurements of emissions. Thus, rigorous evaluation of the new 518 algorithm will require measurement of emissions using the branch enclosure technique, harvesting of 519 foliage and collection of oleoresin from the bole of the tree, and comprehensive, molecular 520 characterization of the essential oil and rosin fractions of foliar and bole oleoresin.

\section{Acknowledgements}


524 The authors acknowledge start-up funding to Paul V. Doskey through Michigan Technological

525 University. Partial support through McIntire Stennis Grant 1001685 from the USDA National Institute of

526 Food and Agriculture is also greatly appreciated. Rosa M. Flores was supported through a fellowship

527 from the Mexican Council of Science and Technology (CONACyT).

528 


\section{References}

Acree, Jr., W.E., 1984. Thermodynamic Properties of Nonelectrolyte Solutions. Academic Press, San Diego, CA.

Canny, M.J., 1995. Apoplastic water and solute movement: New rules for an old space. Annu. Rev. Plant Phys. Plant Molec. Biol. 46, 215-236.

Copolovici L., Niinemets, Ü., 2007. Salting-in and salting-out effects of ionic and neutral osmotica on 538 limonene and linalool Henry's law constants and octanol/water partition coefficients. Chemosphere 69, 621-629.

Eav, J., 2011. Comparison of monoterpene oil composition and volatile emissions from ponderosa and Austrian pine. url, http://nldr.library.ucar.edu/respository/assets/soars/SOARS-000-000-000-226.pdf.

Flores, R.M., 2013. Terpene and Terpenoid Emissions and Secondary Organic Aerosol Production, Ph.D. Dissertation, Michigan Technological University, Houghton, MI. in nonideal liquid mixtures, AIChE J. 21, 1086-1099.

550 Geron, C.D., Guenther, A.B., Pierce, T.E., 1994. An improved model for estimating emissions of volatile organic compounds from forests in the eastern United States, J. Geophys. Res. 99, 12,773-12,791.

552

553 Geron, C., Rasmussen, R., Arnts, R.R., Guenther, A., 2000. A review and synthesis of monoterpene 554 speciation from forests in the United States. Atmos. Environ. 34, 1761-1781. 
556 Guenther, A., Hewitt, C.N., Erickson, D., Fall, R., Geron, C., Graedel, T., Harley, P., Klinger, L., Lerdau, 557 M., McKay, W.A., Pierce, T., Scholes, B., Steinbrecher, R., Tallamraju, R., Taylor, J., Zimmerman, P., 558 1995. A global model of natural volatile organic compound emissions. J. Geophys. Res. 100, 88735598892.

560

561 Guenther, A.B., Jiang, X., Heald, C.L., Sakulyanontvittaya, T., Duhl, T., Emmons, L.K., Wang, X., 2012.

562 The Model of Emissions of Gases and Aerosols from Nature version 2.1 (MEGAN2.1): an extended 563 and updated framework for modeling biogenic emissions. Geosci. Model Dev. 5, 1471-1492.

564

565 Guenther, A.B., Monson, R.K., Fall, R., 1991. Isoprene and monoterpene emission rate variability:

566 Observations with Eucalyptus and emission rate algorithm development, J. Geophys. Res. 96, 10,799-

$567 \quad 10,808$.

568

569 Guenther, A.B., Zimmerman, P.R., Harley, P.C., Monson, R.K., Fall, R., 1993. Isoprene and monoterpene 570 emission rate variability: model evaluations and sensitivity analyses. J. Geophys. Res. 98, 12,609-

$571 \quad 12,617$.

572

573 Guenther, A., Zimmerman, P., Wildermuth, M., 1994. Natural volatile organic emission rate estimates for $574 \quad$ U.S. woodland landscapes. Atmos. Environ. 28, 1197-1210.

Hakola, H., Tarvainen, V., Bäck, J., Ranta, H., Bonn, B., Rinne, J., Kulmala, M., 2006. Seasonal variation of mono- and sesquiterpene emission rates of Scots pine. Biogeosci. 3, 93-101.

578

579 Hanes, C.S., 1927. Resin canals in seedling conifers. Botan. J. Linn. Soc. 47, 613-636. 
Hansen, C.M., 2007. Hansen Solubility Parameters. CRC Press, New York, NY.

Hansen, H.K., Rasmussen, P., Frendenslund, A., Schiller, M., Gmehling, J., 1991. Vapor-liquid-equilibria by UNIFAC group contribution. 5. Revision and extension. Ind. Eng. Chem. Res. 30, 2352-2355.

Helmig, D., Ortega, J., Duhl, T., Tanner, D., Guenther, A., Harley, P., Wiedinmyer, C., Milford, J., Sakulyanontvittaya, T., 2007. Sesquiterpene emissions from pine trees - identifications, emission rates and flux estimates for the contiguous United States. Environ. Sci. Technol. 41, 1545-1553.

Holzke, C., Hoffman, T., Jaeger, L., Koppmann, R., Zimmer, W., 2006. Diurnal and seasonal variation of monoterpene and sesquiterpene emissions from Scots pine (Pinus sylvestris L.). Atmos. Environ. 40, $3174-3185$.

Hrutfiord, B.F., Hopley, S.M., Gara, R.I., 1974. Monoterpenes in Sitka Spruce: Within tree and seasonal variation. Phytochemistry 13, 2167-2170.

596

Jeffrey, E.C., 1925. Resin canals in the evolution of the conifers. PNAS 11, 101-105.

Kanakidou, M., Seinfeld, J.H., Pandis, S.N., Barnes, I., Dentener, F.J., Facchini, M.C., van Dingenen, R., 600 Ervens, B., Nenes, A., Nielsen, C.J., Swietlicki, E., Putaud, J.P., Balkanski, Y., Fuzzi, S., Horth, J., 601 Moortgat, G.K., Winterhalter, R., Myhre, C.E.L., Tsifaridis, K., Vignati, E., Stephanou, E.G., Wilson, 602 J., 2005. Organic aerosol and global climate modeling: a review. Atmos. Chem. Phys. 5, 1053-1123. 603

604 Kulmala, M., Suni, T., Lehtinen, K.E.J., Dal Masso, M., Boy, M., Reissell, A., Rannik, Ü., Aalto, P., 605 Keronen, P., Hakola, H., Bäck, J., Hoffmann, T., Vesala, T., Hari, P., 2004. A new feedback 606 mechanism linking forests, aerosols, and climate. Atmos. Chem. Phys. 4, 557-562. 
608 Langenheim, J.H., 2003. Plant Resins: Chemistry, Evolution, Ecology, and Ethnobotany. Timber Press

609 Inc., Cambridge, U.K.

610

611 Lewinsohn, E., Savage, T.J., Gijzen, M., Croteau, R., 1993. Simultaneous analysis of monoterpenes and 612 diterpenoids of conifer oleoresin. Phytochem. Analysis 4, 220-225.

613

614 Litvak, M.E., Madronich, S., Monson, R.K., 1999. Herbivore-Induced monoterpene emissions from coniferous forests: Potential impact on local tropospheric chemistry. Ecol. Appl. 9, 1147-1159.

616

617 Lohaus, G., Pennewiss, K., Sattelmacher, B., Hussman, M., Muehling, K.H., 2001. Is the infiltration618 centrifugation technique appropriate for the isolation of apoplastic fluid? A critical evaluation with 619 different plant species. Physiol. Plantarum 111, 457-465.

620

621 Mackay, D., Shiu, W.Y., 1981. A critical review of Henry's law constants for chemicals of environmental 622 interest. J. Phys. Chem. Ref. Data 10, 1175-1199.

623

624 Martin, D., Tholl, D., Gershenzon, J., Bohlmann, J., 2002. Methyl jasmonate induces traumatic resin 625 ducts, terpenoid resin biosynthesis, and terpenoid accumulation in developing xylem of Norway spruce 626 stems. Plant Physiol. 129, 1003-1018.

628 Mirov, N.T., 1961. Composition of Gum Turpentines of Pines. Pacific Southwest Forest and Range 629 Experiment Station, U.S. Department of Agriculture, Forest Service, Technical Bulletin No. 1239. 630 
631 Niinemets, Ü., Monson, R.K., Arneth, A., Ciccioli, P., Kesselmeier, J., Kuhn, U., Noe, S.M., Peñuelas, J., 632 Staudt, M., 2010. The leaf-level emission factor of volatile isoprenoids: caveats, model algorithms, 633 response shapes and scaling. Biogeosci. 7, 1809-1832.

634

635 Niinemets, Ü., Loreto, F., Reichstein, M., 2004. Physiological and physicochemical controls on foliar 636 volatile organic compound emissions. Trends Plant Sci. 9, 180-186.

637

638 Niinemets, Ü., Reichstein, M., 2002. Effects of nonspecific monoterpenoid storage in leaf tissues on 639 emission kinetics and composition in Mediterranean scerophyllous Quercus species: a model analysis.

640 Global Biogeochem. Cy. 16, 1110 doi: 10.1029/2002GB001927.

641

642

Ortega, J., Helmig, D., Daly, R.W., Tanner, D.M., Guenther, A.B., Herrick, J.D., 2008. Approaches for 643 quantifying reactive and low-volatility biogenic organic compound emissions by vegetation enclosure 644 techniques - Part B: Applications. Chemosphere 72, 365-380.

645

646 Pankow, J.F., Asher, W.E., 2008. SIMPOL.1: A simple group contribution method for predicting vapor 647 pressures and enthalpies of vaporization of multifunctional organic compounds. Atmos. Chem. Phys. 8, 2773-2796.

649

Prausnitz, J.M., Lichenthaler, R.N., Gomes de Azevedo, E., 1999. Molecular Thermodynamics of FluidPhase Equilibria. Prentice-Hall, Upper Saddle River, NJ. 348-355. 
von Rudloff, E., 1972. Seasonal variation in the composition of the volatile oil of the leaves, buds, and

657 twigs of white spruce (Picea glauca). Can. J. Bot. 50, 1595-1603.

658

von Rudloff, E., 1975. Volatile leaf oil analysis in chemosystematic studies of North American conifers.

$660 \quad$ Biochem. Syst. Ecol. 2, 131-167.

661

662 Setschenow, J., 1889. Über die Konstitution der Salzlösungen auf Grund ihres Verhaltens zu

663 Kohlensäure. Z. Phys. Chem. 4, 117-125.

664

665

Suzuki, M., 1979. The course of resin canals in the shoots of conifers III. Pinaceae and summary

666 analysis. Bot. Mag. Tokyo 92, 333-353.

667

668

Thibodeaux, L.J., 1996. Environmental Chemodynamics. John Wiley and Sons, New York.

669

Tingey, D.T., Manning, M., Grothaus, L.C., Burns, W.F., 1980. Influence of light and temperature on monoterpene emission rates from slash pine. Plant Physiol. 65, 797-801.

Tingey, D.T., Turner, D.P., Weber, J.A., 1991. Factors controlling the emissions of monoterpenes and 674 other volatile organic compounds. In Trace Gas Emissions by Plants, Sharkey, T.D., Holland, E.A., Mooney, H.A., eds. pp. 93-119, Academic Press, San Diego, CA.

676

677 Toma, S., Bertman, S., 2012. The atmospheric potential of biogenic volatile organic compounds from needles of white pine (Pinus strobus) in Northern Michigan. Atmos. Chem. Phys. 12, 2245-2252. 679

680 Yatagai, M., Sato, T., 1986. Terpenes of leaf oils from conifers. Biochem. Syst. Ecol. 14, 469-478. 681 
682 Zavarin, E., 1968. Chemotaxonomy of the genus Abies-II. Within tree variation of the terpenes in 683 cortical oleoresin. Phytochemistry 7, 92-107.

684

685 Zulak, K.G., Bohlmann, J., 2010. Terpenoid biosynthesis and specialized vascular cells of conifer 686 defense. J. Integr. Plant Biol. 52, 86-97.

687 
688

689

690

Table 1. Molar volumes $(V)$, Hansen solubility parameters for dispersive $\left(\delta_{d}\right)$, polar $\left(\delta_{p}\right)$, and H-bonding $\left(\delta_{h}\right)$ interactions, and activity coefficients $(\gamma)$.

\begin{tabular}{lcccccc}
\hline Chemical Species & $\begin{array}{c}V \\
\left(\mathrm{~cm}^{3} \mathrm{~mol}^{-1}\right)\end{array}$ & $\begin{array}{c}\delta_{d} \\
\left(\mathrm{cal}^{1 / 2} \mathrm{~cm}^{-3 / 2}\right)\end{array}$ & $\begin{array}{c}\delta_{p} \\
\left(\mathrm{cal}^{1 / 2} \mathrm{~cm}^{-3 / 2}\right)\end{array}$ & $\begin{array}{c}\delta_{h} \\
\left(\mathrm{cal}^{1 / 2} \mathrm{~cm}^{-3 / 2}\right)\end{array}$ & $\gamma_{M T}$ & $\gamma_{R A}$ \\
\hline$\alpha$-Pinene & 151.5 & 8.08 & 0.72 & 1.54 & 1.01 & 1.22 \\
Camphene & 149.1 & 7.90 & 0.76 & 1.55 & 1.03 & 1.30 \\
$\beta$-Pinene & 149.1 & 8.16 & 0.76 & 1.55 & 1.00 & 1.17 \\
Myrcene & 172.2 & 7.49 & 1.09 & 2.50 & 1.21 & 1.67 \\
$\alpha$-Phellandrene & 165.6 & 7.72 & 0.83 & 2.09 & 1.08 & 1.32 \\
Limonene & 161.3 & 7.95 & 1.01 & 2.11 & 1.03 & 1.14 \\
$\beta$-Phellandrene & 163.2 & 7.79 & 0.86 & 2.10 & 1.06 & 1.25 \\
$\delta$-Terpinene & 161.8 & 8.03 & 1.11 & 2.11 & 1.02 & 1.16 \\
$\alpha$-Terpineol & 162.6 & 8.37 & 2.69 & 5.55 & 3.10 & 1.70 \\
$\beta$-Caryophyllene & 273.0 & 7.67 & 0.77 & 1.62 & 1.07 & 2.42 \\
Germacrene D & 252.9 & 7.78 & 0.89 & 2.07 & 1.03 & 1.78 \\
Germacrene D-4-ol & 273.2 & 7.79 & 2.07 & 4.43 & 2.03 & 2.33 \\
Levopimaric Acid & 279.9 & 9.00 & 1.28 & 3.52 & 1.58 & 1.03 \\
OR $_{\mathrm{MT}}{ }^{\mathrm{b}}$ & 177.2 & 8.26 & 0.83 & 1.94 & & \\
OR $_{\text {RA }}$ & 254.2 & 8.82 & 1.17 & 3.12 & & \\
\hline
\end{tabular}

${ }^{\mathrm{a} O l e o r e s i n}$ composition: $80 \% \alpha$-pinene and $20 \%$ levopimaric acid.

693 bleoresin composition: $80 \%$ levopimaric acid and $20 \% \alpha$-pinene. 

emission rates of terpenes and terpenoids.

698

\begin{tabular}{lccccc}
\hline Chemical Species & $\begin{array}{c}\Delta H_{v}{ }^{a} \\
\left(\mathrm{~kJ} \mathrm{~mol}^{-1}\right)\end{array}$ & $\begin{array}{c}p^{d} \\
(\mathrm{~mm} \mathrm{Hg})\end{array}$ & $\begin{array}{c}\text { Measured } \\
\text { Emission Rate }^{\mathrm{c}}{ }^{\left(\mu \mathrm{g} \mathrm{Cdw}^{-1} \mathrm{~h}^{-1}\right)}\end{array}$ & $\begin{array}{c}\text { Predicted } \\
\text { Emission Rate }^{\mathrm{e}} \\
\left(\mu \mathrm{g} \mathrm{Cgdw}^{-1} \mathrm{~h}^{-1}\right)\end{array}$ & $\begin{array}{c}\text { Predicted } \\
\text { Emission Rate }^{\mathrm{f}} \\
\left(\mu \mathrm{g} \mathrm{C} \mathrm{gdw}^{-1} \mathrm{~h}^{-1}\right)\end{array}$ \\
\hline$\alpha$-Pinene & 54.2 & 2.22 & 0.20 & 0.38 & 1.3 \\
Camphene & 54.2 & 2.22 & 0.072 & 0.053 & 0.17 \\
$\beta$-Pinene & 54.2 & 2.22 & 0.14 & 0.28 & 0.97 \\
Myrcene & 56.3 & 1.42 & 0.090 & 0.049 & 0.17 \\
$\alpha$-Phellandrene & 53.0 & 1.73 & 0.018 & 0.017 & 0.055 \\
Limonene & 53.0 & 1.73 & 0.044 & 0.026 & 0.090 \\
$\beta$-Phellandrene & 53.0 & 1.73 & 0.049 & 0.023 & 0.075 \\
-Terpinene & 53.0 & 1.73 & 0.011 & 0.0044 & 0.016 \\
$\alpha$-Terpineol & 71.3 & $1.46 \mathrm{E}-02$ & 0.0071 & 0.00017 & 0.00080 \\
$\beta$-Caryophyllene & 69.5 & $1.24 \mathrm{E}-02$ & 0.018 & 0.00098 & 0.00034 \\
Germacrene D & 72.8 & $1.02 \mathrm{E}-02$ & 0.0099 & 0.00016 & 0.0015 \\
Germacrene D-4-ol & 91.1 & $2.99 \mathrm{E}-04$ & $\mathrm{~d}$ & 0.000039 & 0.00018 \\
\hline
\end{tabular}

Germacrene D-4-o

$91.1 \quad 2.99 \mathrm{E}-04$

\section{8).}

$701{ }^{\mathrm{b}}$ Estimated at $25^{\circ} \mathrm{C}$ using SIMPOL.1 (Pankow and Asher, 2008).

$702{ }^{c}$ (Ortega et al., 2008).

$703{ }^{\mathrm{d}}$ Not measured.

704 e Predicted using the mole fractions in oleoresin estimated from the data of Toma and Bertman (2012) and

705 Mirov (1961) and an oleoresin containing 75\% levopimaric acid and 25\% $\alpha$-pinene.

$706{ }^{\mathrm{f}}$ Predicted using the average mole fraction in foliar oils (Toma and Bertman, 2012) and an oleoresin

707 composition containing $25 \%$ levopimaric acid and $75 \% \alpha$-pinene. 
Figure 1. Mixing ratios $\left(\mathrm{ppb}_{\mathrm{v}}\right)$ of terpenes and terpenoids in equilibrium with a monoterpene-rich and resin-acid-rich oleoresin (i.e., $80 \% \alpha$-pinene, $20 \%$ pimaric acid and $20 \% \alpha$-pinene and $80 \%$ pimaric acid, respectively).

Figure 2. Correlation between the mole fraction of terpenes and terpenoids in foliar oleoresin of Pinus strobus and the mole fraction in emissions. Mole fractions were estimated from foliar oleoresin composition (Toma and Bertman, 2012) and emission rates (Ortega et al., 2008). (Camphene, Germacrene D, and Myrcene are the principal outliers.)

Figure 3. Variation in the $\alpha$-pinene emission rate $\left(\mu \mathrm{g} \mathrm{Cgdw}^{-1} \mathrm{~h}^{-1}\right)$ for Pinus species and the vapor pressure (mm Hg) of $\alpha$-pinene with temperature. Emission rates were estimated using Eqn. (1) and the range and average value of $\beta$ for $\alpha$-pinene emitted from 7 species of Pinus (Guenther et

Figure 4. Variation in monoterpene emission rates $\left(\mu \mathrm{g} \mathrm{Cgdw}{ }^{-1} \mathrm{~h}^{-1}\right)$ for Pinus elliotii (Tingey et al., 1980) al., 1993) and a value of $3.0 \mu \mathrm{g} \mathrm{C} \mathrm{gdw}{ }^{-1} \mathrm{~h}^{-1}$ for $E_{S}$ of Pinus (Geron et al., 1994). Values of $\Delta H_{v i}$ and $p^{\circ}{ }_{i}$ at $25^{\circ} \mathrm{C}$ for $\alpha$-pinene were estimated by the SIMPOL.1 method (Table 2; Pankow and Asher, 2008) and used in Eqn. (18) to estimate vapor pressures. and monoterpene vapor pressures $(\mathrm{mm} \mathrm{Hg})$ with needle temperature. Values of $\Delta H_{v i}$ and $p^{\circ}{ }_{\mathrm{i}}$ at $25^{\circ} \mathrm{C}$ for the monoterpenes were estimated by the SIMPOL.1 method (Table 2; Pankow and Asher, 2008) and used in Eqn. (18) to estimate monoterpene vapor pressures.

Figure 5. Correlation between emission rates $\left(\mu \mathrm{g} \mathrm{C} \mathrm{gdw}^{-1} \mathrm{~h}^{-1}\right)$ predicted from foliar oil composition reported by Toma and Bertman (2012) and measured emissions rates (Ortega et al., 2008) of 

principal outliers.)

735 
Fig. 1.

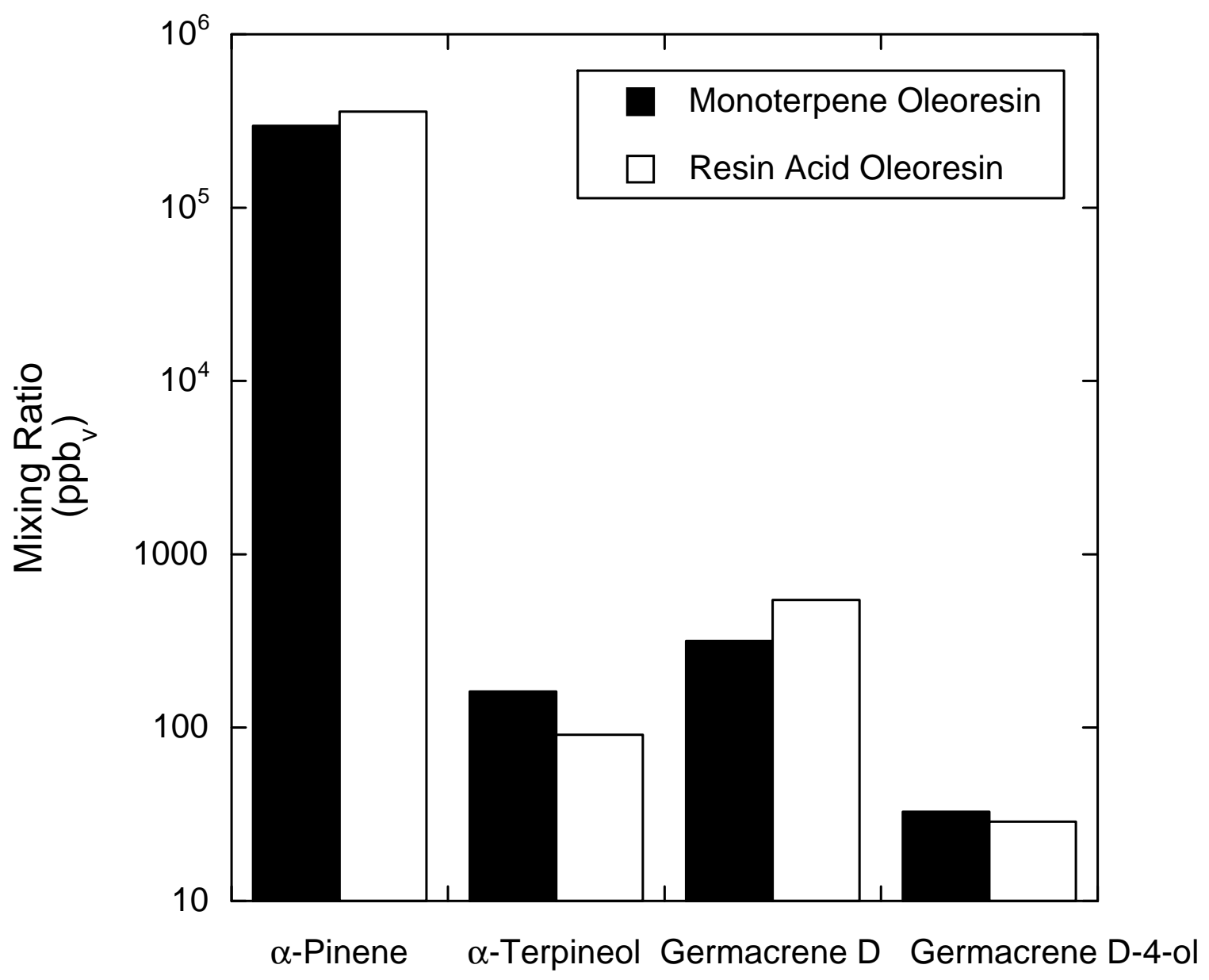




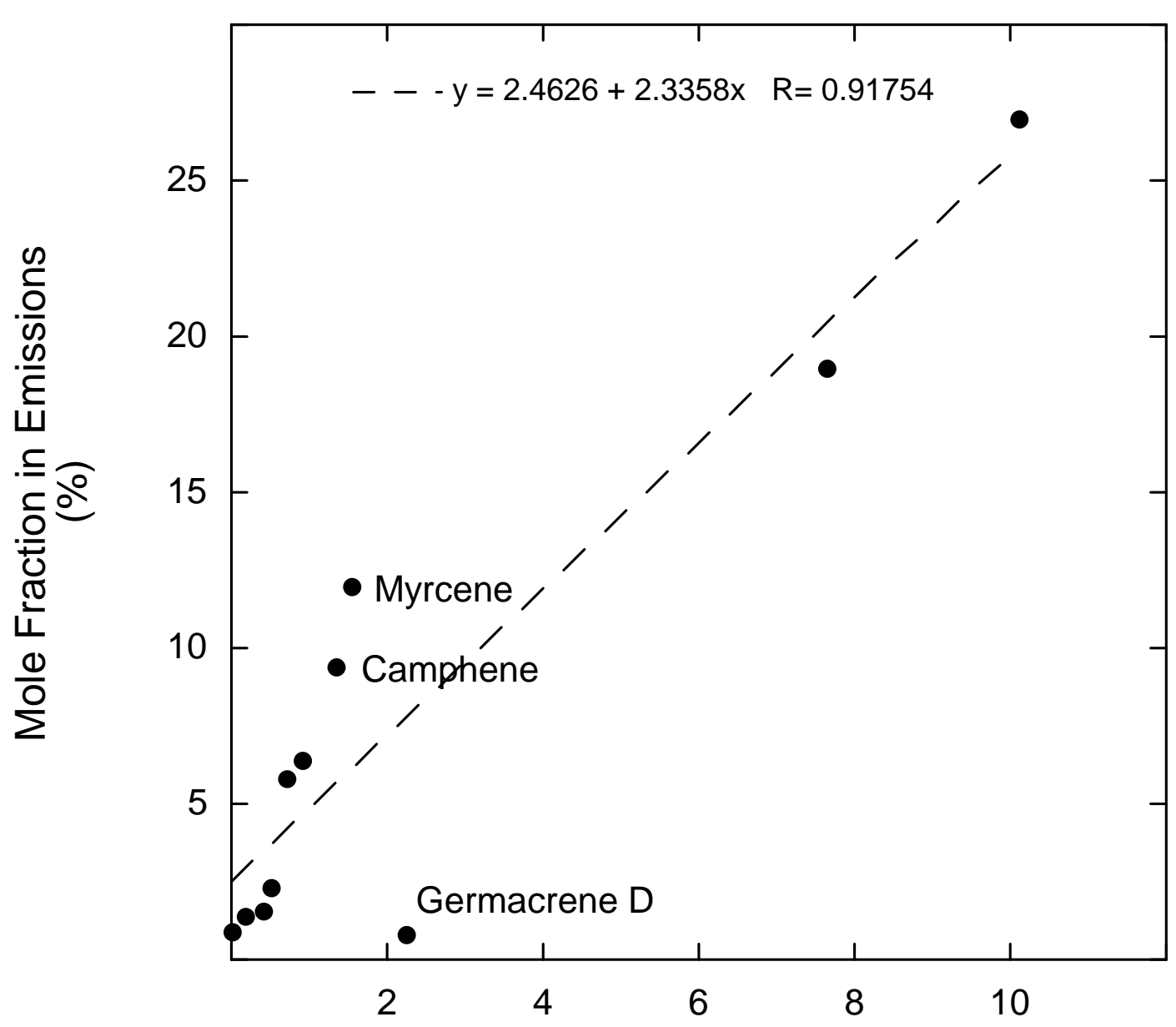

Mole Fraction in Foliar Oleoresin 
Fig. 3.

753

754

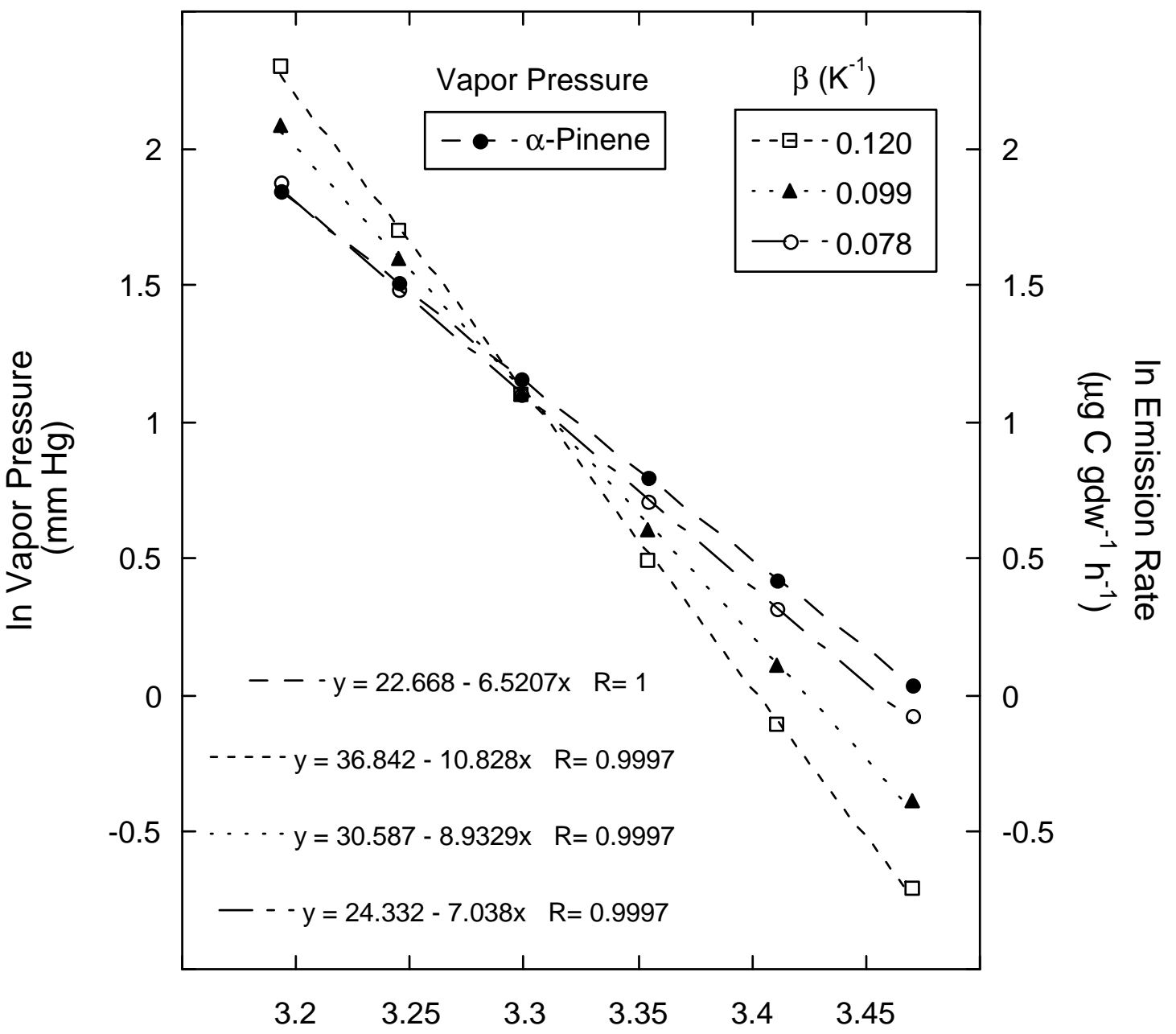

755

Temperature $^{-1}$

$\left(\mathrm{K}^{-1} \times 10^{3}\right)$

756

757 
Fig. 4.

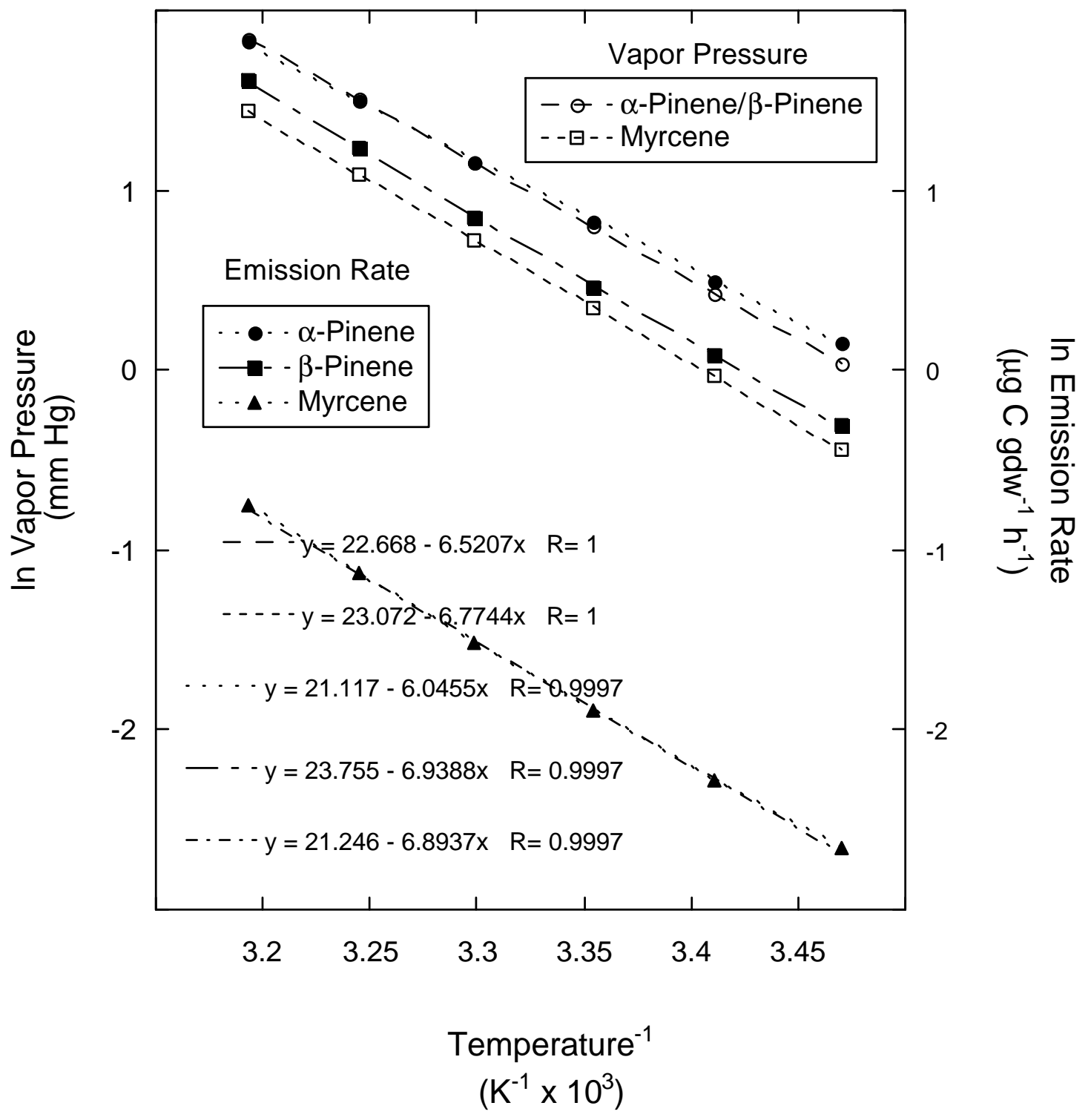

762

763 
767

768

769

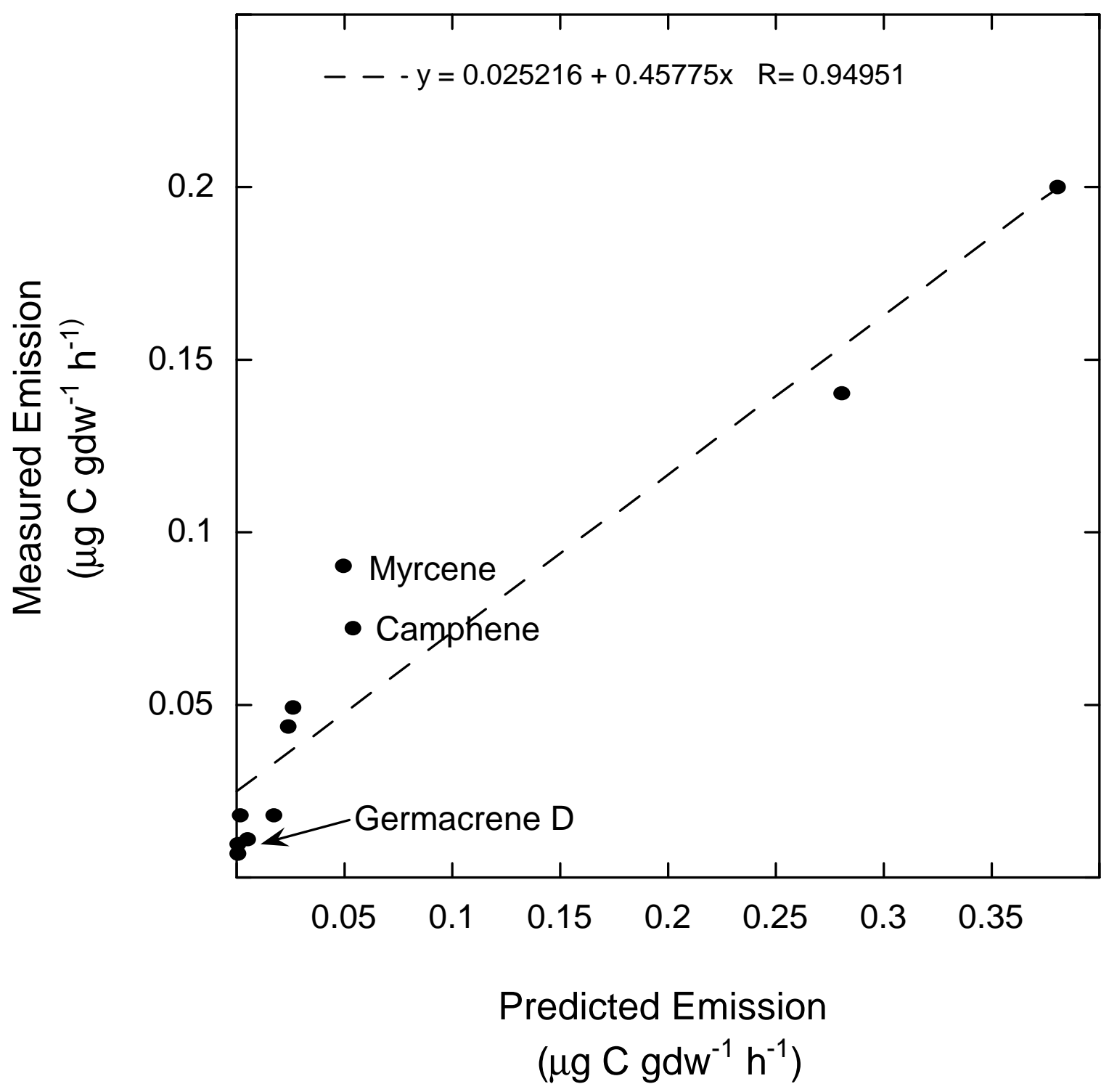

